\title{
STRUCTURE PROPERTY CORRELATION OF AL BASED BERYL REINFORCED METAL MATRIX COMPOSITE
}

\author{
S.K. Rajendra ${ }^{1}$, C.M. Ramesha ${ }^{2}$
}

Abstract: Aluminium based metal matrix composites (AMMC) containing beryl (10\%, 20\% and 30\%) were fabricated using two powder metallurgy routes i.e. microwave and vacuum sintering respectively and investigated for the sake of optimization of mechanical properties like constitutive and wear. The material has a novelty of being fabricated using a mineralized reinforcement like beryl and strong interfacial coherency can be maintained which has finally been fabricated and engineered for better combination of strength i.e. hardness, YS and UTS and ductility as confirmed from the constitutive parameters like $\mathrm{n}, \mathrm{K}$ etc. It has been observed that the microwave sintered samples exhibit better density and this better densification leads to better sliding wear properties.

Keywords: Beryl; Metal matrix composite; Vacuum and Microwave sintering; Interface; Powder metallurgy

\section{INTRODUCTION}

Aluminium based MMCs are predicted to have good application in automotive and aerospace sectors. Cost effectiveness, availability, good strength and ductility and formability of Aluminium leads to the establishment of it as the unputdownable material for aerospace sectors. Reinforcements in various forms has been used and proposed to be used in different parts where the Al based components are proposed to be used. Composites are essentially tailored and engineered for a particular application and it has very good directional properties. [1-4], The need of automotive and aerospace sectors is the superior physical, mechanical, and tribological properties. In order to achieve this, incorporation of second phase particles such as $\mathrm{Al} 2 \mathrm{O} 3, \mathrm{SiC}$, TiN, and TiO2 have been attempted. Most of the studies showed that the ceramic particles have high hardness, and high density. Beryl is a mineral that has abundance in earth's crust. To mineralogists, it is known as goshenite and to chemists as beryllium aluminium cyclosilicate Be3A12(Si O3)6 having similar density of that of the Aluminium that ensures better amalgamation. (Reference: Thomas, Arthur (2008). Gemstones: Properties, Identification and Use. London: New Holland. pp. 77-78. ISBN 978-1-84537-602-4) For the cost reduction use of beryl as a reinforcement is a novel idea due to their abundance in Karnataka state of India. A large number of processing methods were used in the synthesis Al based Metal Matrix Composites. Liquid metallurgy vortex route was one of the most elaborative methods [5, 6]. In this method, settling of ceramic particles was the limitation. Preparation of metal matrix composites are economical and advantage as compared to ingot metallurgy or diffusion welding,

\footnotetext{
1 Jain University, Bengaluru, and Associate Professo, r Department of Industrial Engineering and Management Dr Ambedkar Institute of Technology, Bengaluru-560056, India 2 Department of Mechanical Engineering, M. S Ramaiah Institute of Technology, Bengaluru-560 054, India
} 
the main advantage is low manufacturing temperature that avoids strong interfacial reaction, thereby minimizing the undesired reactions between the matrix and the reinforcement. For testing small specimens, Ball indentation tests have been reckoned as a wonderful technique and it is popularly used to assess the properties of cast iron (Reference: Ray, K. K., et al. "Development of Ductile Cast Iron for Spent Fuel Cask Applications Using Fracture Mechanics Principles." Transactions of the Indian Institute of Metals 69.2 (2016): 635-639) and of SPD products (Reference: Das, Goutam, et al. "Effect of aging on mechanical properties of 6063 Alalloy using instrumented ball indentation technique." Materials Science and Engineering: A 527.6 (2010): 1590-1594). The data obtained by this method is in superb correlation with the data obtained in mechanical methods of coupon testing and the results are capable of mapping site specific mechanical properties and that popularizes its use among the other non-conventional testing methods. Therefore, we have chosen Ball indentation as a method for estimating mechanical properties in this work. The present investigation is aimed with six specific points. (1) Selection of ceramic particles such as beryl with a density of $\sim 2.65 \mathrm{~g} / \mathrm{cc}$, which is lighter than other ceramic particles such as $\mathrm{SiC}, \mathrm{Al} 2 \mathrm{O} 3$, TiN, and has similar density of Al. The beryl has a hardness ranging from 7.5 to 8.5 Mho's scale, (2) Fabricate Al based MMCs using beryl as reinforcing particles using powder metallurgy route, (3) Investigating the microstructural evolution, (4) Mechanical property evaluation by Ball Indentation Test, (5) Wear studies, (6) Study the influence of beryl particle sizes in synthesizing aluminum metal matrix composites in vacuum and microwave sintering.

\section{EXPERIMENTAL PROCEDURE}

Commercially available Al powder with average particle size of $20 \pm 5 \mu \mathrm{m}$ of Leo chemicals was taken as starting material. Beryl, abundantly available in Karnataka region in the form of mineral phase was selected. The beryl was initially crushed, and mechanically sieved to various particle sizes. The average particle sizes of 50 and $100 \mu \mathrm{m}$ were considered. The beryl powders were cleaned in acetone, and then washed thoroughly.

Beryl powders with average particle sizes of 50 and $100 \mu \mathrm{m}$ were individually taken, and finally Al-beryl MMCs were fabricated. A very limited research work has been carried out on synthesis of Al-beryl MMCs [7-9]. The beryl content was varied from 10, 20 and 30-wt\%. They were coated with nickel by electro less deposition in commercially available Al powder. The powder mixture was thoroughly mixed using agate motor by adding a poly vinyl alcohol and a green cylindrical pellet of $25 \mathrm{~mm}$ diameter were prepared by applying a $1.02 \mathrm{MPa}$ pressure. The pellets were sintered at $600^{\circ} \mathrm{C}$ in vacuum/inert atmosphere graphite furnace at Therlex Engineers (p) Ltd, Bangalore. All samples after sintering were metallographically prepared and observed under optical and SEM. Hardness measurements were taken using standard Vickers hardness tester, and the ball indentation technique used to measure and compares the mechanical properties through true stress Vs true strain plots. The ball indentation technique used to measure yield strength (YS), ultimate tensile strength (UTS), strain hardening exponent(n), strength coefficient $(\mathrm{K})$, fracture toughness(Ktc), hardness(BHN) and young's modulus.

\section{RESULTS AND DISCUSSION}

\subsection{Commercial Pure Aluminum}

Table 1.0 shows the chemical composition of commercial pure Al. A wet chemical analysis method is used to analyze the presence of elements in Al. It shows minor alloying such as Fe, 
and $\mathrm{Si}$ are $0.17 \mathrm{wt} . \%$, and $0.11 \mathrm{wt} \%$ respectively. Figure 1.0 indicates the SEM photomicrographs of $\mathrm{Al}$ powder. It is clear from the figure that the $\mathrm{Al}$ particles are gray in color, Irregular in size. The average particle size of Al powder is $\sim 20 \pm 5 \mu \mathrm{m}$. Figure 2.0 shows the optical images of $\mathrm{Al}$ at different magnifications. It is clearly show the presence of grain boundaries in $\mathrm{Al}$ matrix. Figure 3.0 shows the XRD pattern of commercial pure Al XRD results suggest that, all major peaks are recognized as of Al. As expected, the major peak contains (200) plane and other planes such as (111), (220), (211) are also present. No peaks of aluminum oxide $\left(\mathrm{Al}_{2} \mathrm{O}_{3}\right)$ and $\mathrm{Si}$ were found in the pattern, which indicates that, it is mostly Al. Since the volume fraction of $\mathrm{Fe}, \mathrm{Si}$ and $\mathrm{O}$ are very less, no peaks are observed.

Table 1.0 Chemical composition (wt. \%) of commercial purity Al

\begin{tabular}{|l|l|l|}
\hline Fe & Si & Al \\
\hline 0.17 & 0.11 & 99.72 \\
\hline
\end{tabular}

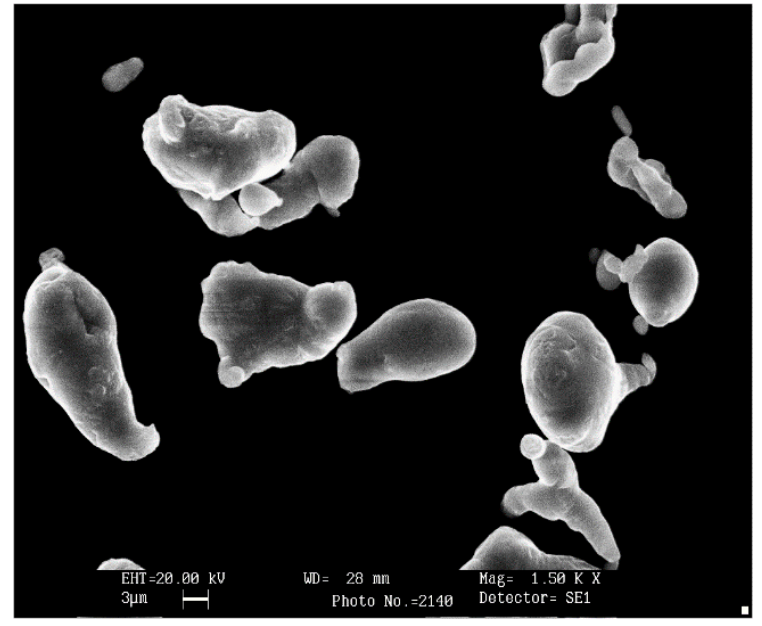

Figure 1.0: SEM image of commercial pure aluminium powder
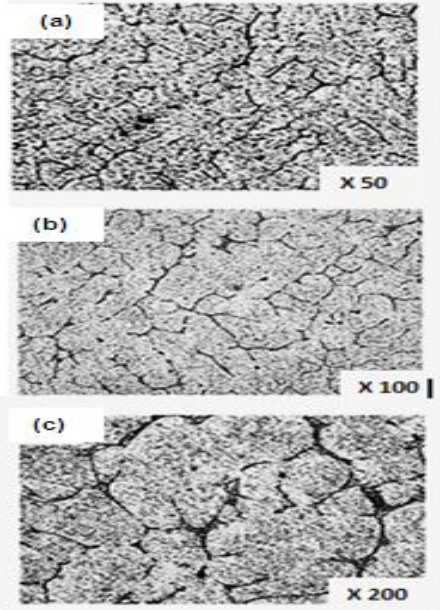

Figure 2.0: Optical images of CPAl at different magnifications

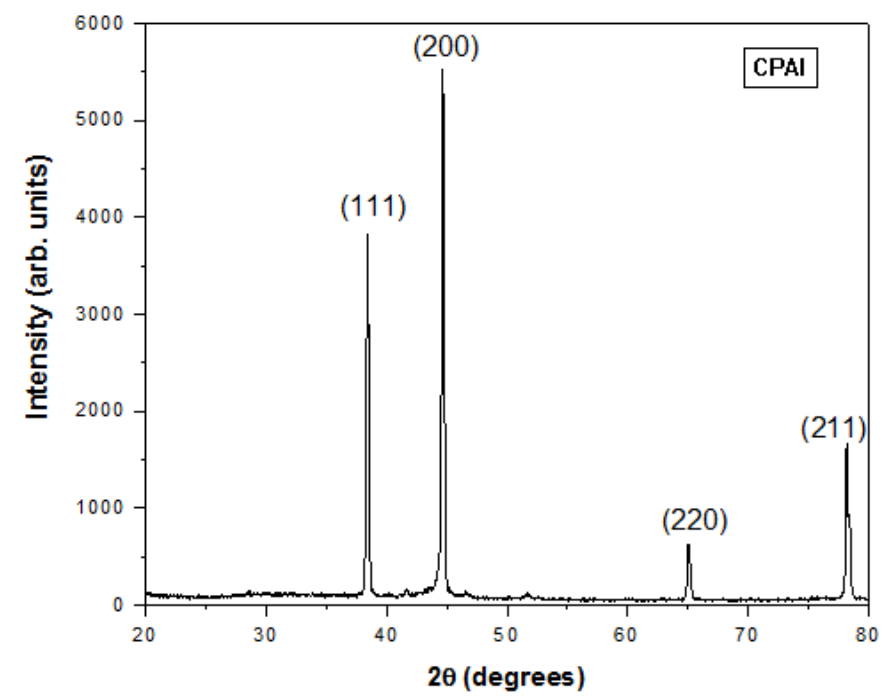

\subsection{Beryl}

Figure 3.0: X-ray diffraction of commercial pure aluminium 
Table 2.0 shows the EDX results and confirms the presence of $\mathrm{Al}, \mathrm{O}, \mathrm{Si}$. However, $\mathrm{Be}$ is not confirmed due to the limitation of the SEM/EDX. The chemical composition of beryl is given in table 2.0. Table 3.0 depicts the various phases present in beryl powder. Basically beryl contains mostly $\mathrm{SiO}_{2}, \mathrm{Al}_{2} \mathrm{O}_{3}$, and $\mathrm{BeO}$. The other minor phases present in beryl are $\mathrm{Fe}_{3} \mathrm{O}_{3}, \mathrm{CaO}, \mathrm{MgO}$, $\mathrm{Na}_{2} \mathrm{O}, \mathrm{K}_{2} \mathrm{O}$ and $\mathrm{MnO}$.

Table 2.0: EDX result of beryl powder

\begin{tabular}{|l|l|l|l|}
\hline Element & Spectrum Type & $\begin{array}{l}\text { Element } \\
\boldsymbol{\%}\end{array}$ & $\begin{array}{l}\text { Atomic } \\
\boldsymbol{\%}\end{array}$ \\
\hline $\mathrm{O} \mathrm{K}$ & ED & 60.86 & 73.16 \\
\hline $\mathrm{Na} \mathrm{K}$ & ED & 0.34 & 0.28 \\
\hline $\mathrm{Mg} \mathrm{K}$ & ED & 0.15 & 0.12 \\
\hline $\mathrm{Al} \mathrm{K}$ & ED & 8.37 & 5.97 \\
\hline $\mathrm{Si} \mathrm{K}$ & ED & 29.53 & 20.22 \\
\hline $\mathrm{Fe} \mathrm{K}$ & ED & 0.76 & 0.26 \\
\hline Total & & 100.00 & 100.00 \\
\hline
\end{tabular}

Table 3.0: Chemical composition of beryl powder

\begin{tabular}{|l|l|}
\hline Test Parameter & Vol \% \\
\hline Silica as $\mathrm{SiO}_{2}$ & 57.44 \\
\hline Alumina as $\mathrm{Al}_{2} \mathrm{O}_{3}$ & 21.01 \\
\hline Beryl oxide as $\mathrm{BeO}$ & 16.82 \\
\hline Iron oxide as $\mathrm{Fe}_{2} \mathrm{O}_{3}$ & 1.31 \\
\hline Calcium Oxide as $\mathrm{CaO}$ & 1.09 \\
\hline Magnesium Oxide as $\mathrm{MgO}$ & 0.56 \\
\hline Sodium Oxide as $\mathrm{Na}_{2} \mathrm{O}$ & 0.017 \\
\hline Potassium Oxide as $\mathrm{K}_{2} \mathrm{O}$ & 1.56 \\
\hline Manganese Oxide as $\mathrm{MnO}$ & 0.017 \\
\hline
\end{tabular}
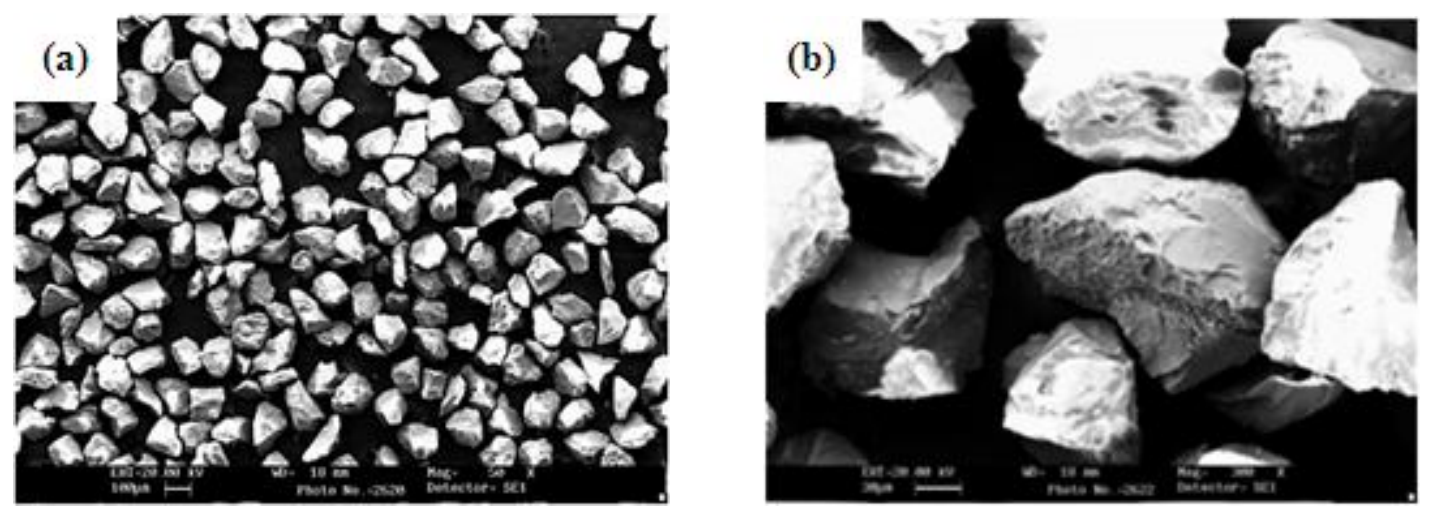

Figure 4.0 (a, b): SEM images of uncoated beryl particles at different magnifications

Figure 4.0 shows the SEM image of as received beryl powder. An observation of the image reveals that the particles are of irregular in size. Most of the particles are faceted in nature and 
due to its fineness, some agglomeration is also observed. The most important physical property of particulate sample is particle size. Particle size distributions and understanding its effect in characterization of composites is an important study. The beryl rocks are crushed and ball milled to yield a fine powder. Finally, fine powder is sieved to yield 2 batches with an average particle size of $\sim 110$, and $50 \mu \mathrm{m}$. This clearly demonstrates that mechanical sieving for $2 \mathrm{~h}$ is sufficient as the particle size analysis range is in the size range from 50 to $100 \mu \mathrm{m}$. Figure 5.0 shows the beryl particle size distribution, high volume fraction is of average particle size is $\sim 100 \mu \mathrm{m}$, and $\sim 50$ $\mu \mathrm{m}$
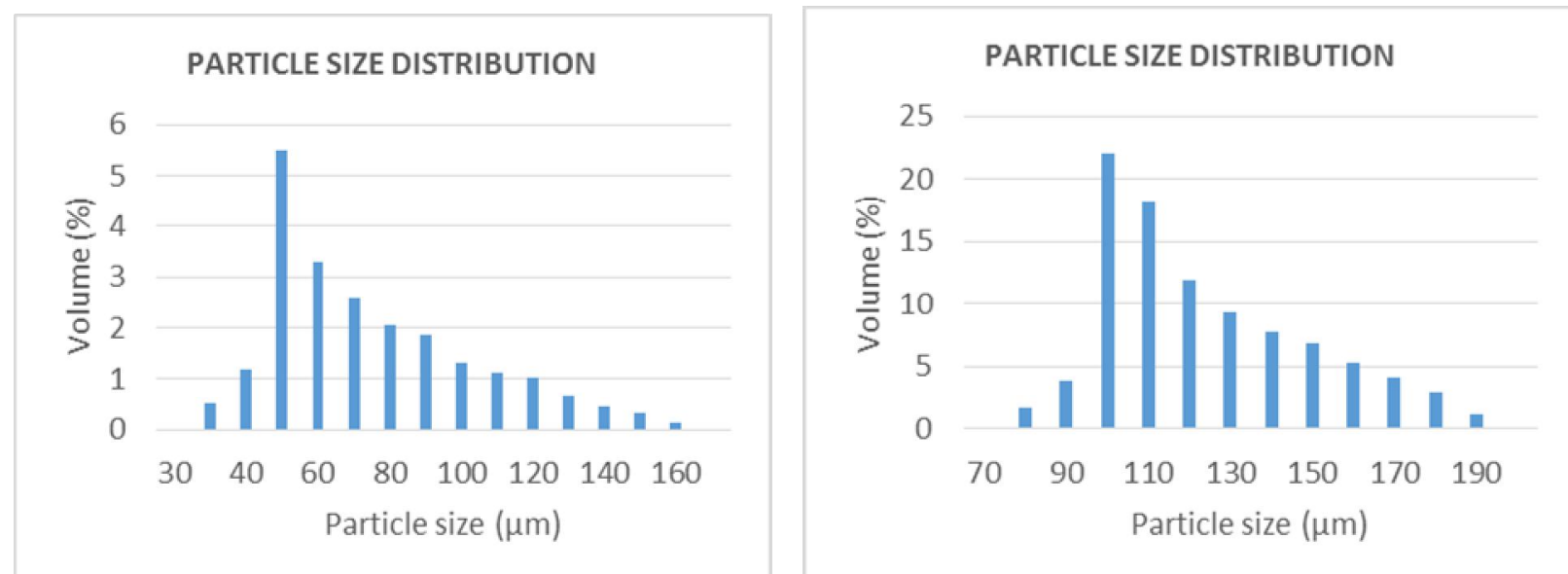

Figure $5.0(a, b)$ : Particle size distribution of sieved average particle size of beryl powder, (a) $100 \mu \mathrm{m}$, and (d) 50 $\mu \mathrm{m}$

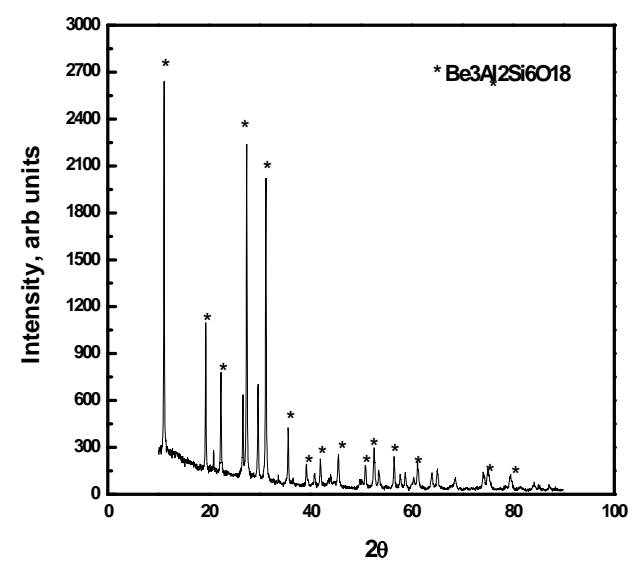

Figure 6.0: X-ray diffraction analysis of beryl particles

Figure 6.0 shows $\mathrm{X}$-ray diffraction pattern of beryl particles to identify the mineral phases. The XRD spectrum reveals the presence $\mathrm{Be}_{3} \mathrm{Al}_{2} \mathrm{Si}_{6} \mathrm{O}_{18}$ peaks and confirms these are beryl peaks. The present results also further confirm that that there are no other phases.

\subsection{MICROSTRUCTURAL STUDIES}



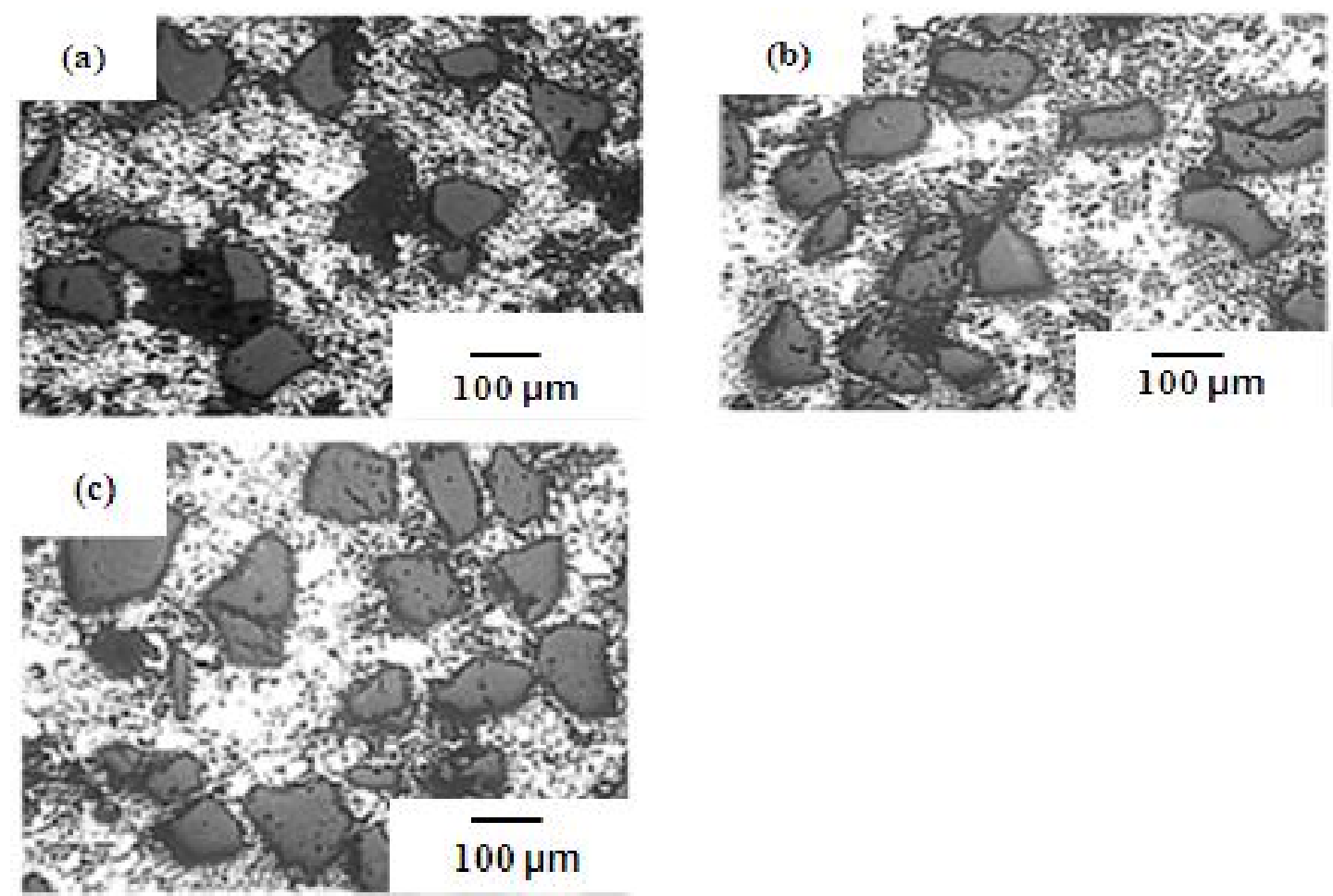

Figure 7.0: Optical images of $\mathrm{Al}-10$ beryl, $\mathrm{Al}-20$ beryl, and $\mathrm{Al}-30$ beryl composites, containing average beryl particle size of $100 \mu \mathrm{m}$, vacuum sintered at $600^{\circ} \mathrm{C}(\mathrm{X} 50)$
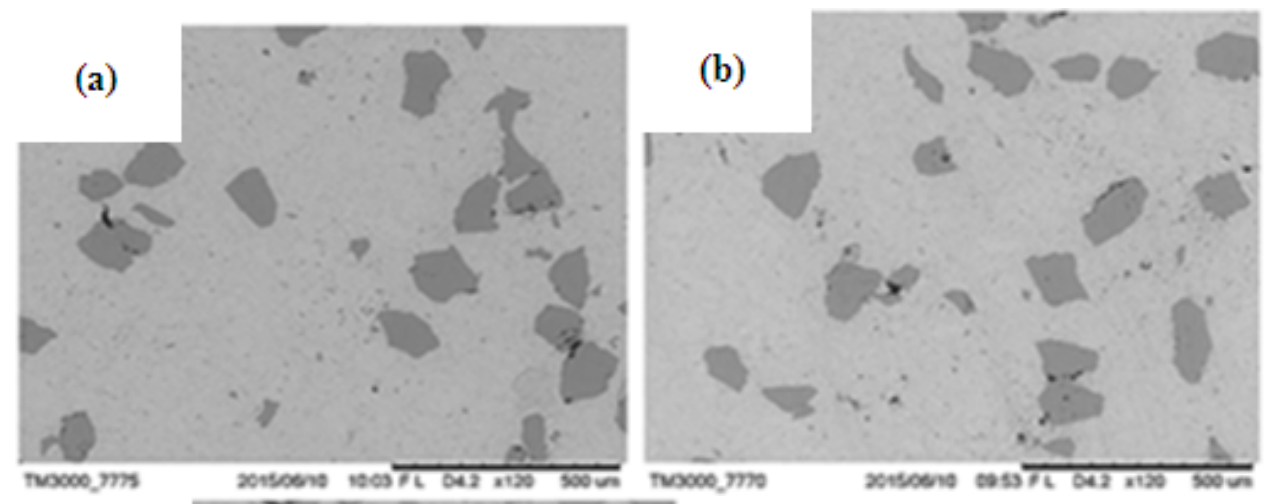

(c)

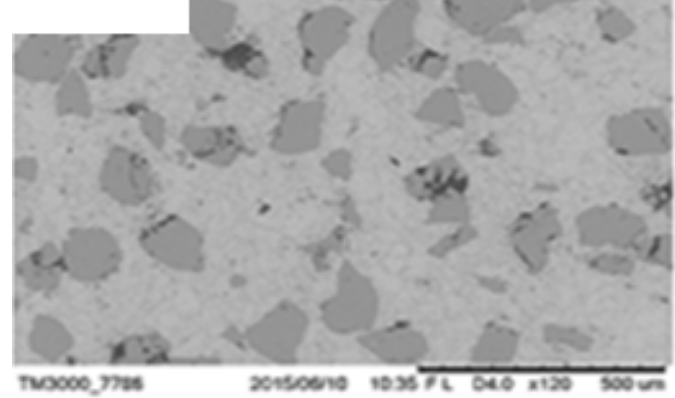

Figure 8.0: SEM images of $\mathrm{Al}-10$ beryl, $\mathrm{Al}-20$ beryl and $\mathrm{Al}-30$ beryl composites, containing average beryl particle size of $100 \mu \mathrm{m}$, vacuum sintered at $600^{\circ} \mathrm{C}$,

(a) $\mathrm{Al}-10$ wt. \% beryl, (b) $\mathrm{Al}-20$ wt. \% beryl, and (c) $\mathrm{Al}-30$ wt. \% beryl 

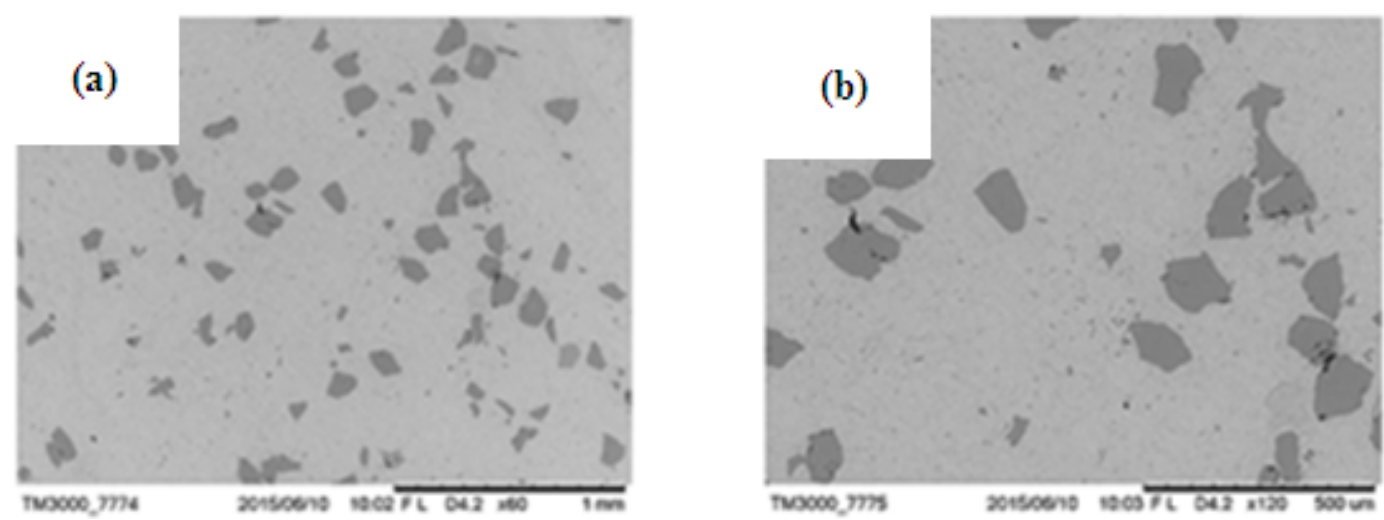

(c)
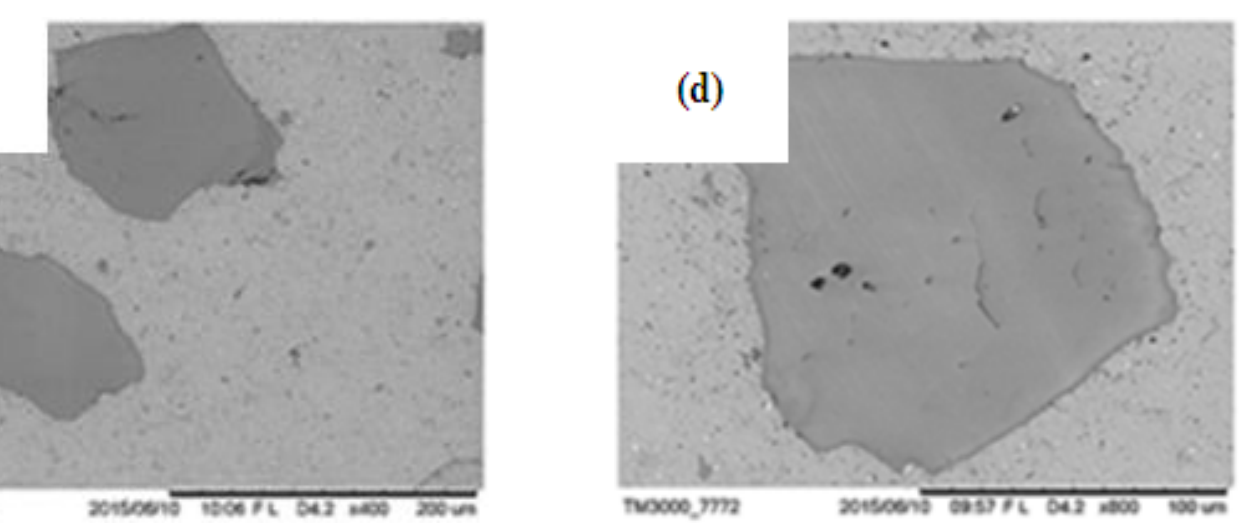

Figure 9.0: SEM images of vacuum sintered Al- $10 \mathrm{wt}$ \% beryl composite, containing average beryl particle size of $100 \mu \mathrm{m}$ at different magnification

\subsection{Ball indentation tests}

The ball indentation technique is used to evaluate the mechanical properties of Al-beryl MMCs. The beryl particles in aluminium is $10 \mathrm{wt} . \%$, the average size of the beryl particles are $\sim 100 \mu \mathrm{m}$ and $\sim 50 \mu \mathrm{m}$. The Ball indentation technique estimates the strain hardness coefficient (n), the strength coefficient (K) the yield strength (YS), the ultimate tensile strength (UTS) and the Brinell hardness number (BHN).

Table 4.0: Mechanical properties of Al-beryl MMC processed through vacuum sintering at a temperature of $600^{\circ} \mathrm{C}$, consisting 10 wt. \% beryl, and average size of beryl particle is 100 $\mu \mathrm{m}$

\begin{tabular}{|l|l|l|l|l|l|l|l|l|}
\hline \multirow{2}{*}{ Sample name } & $\begin{array}{l}\text { True Stress } \\
\text { (MPa) }\end{array}$ & $\begin{array}{l}\text { True } \\
\text { strain }\end{array}$ & $\begin{array}{l}\text { True } \\
\text { Stress } \\
(\mathbf{M P a})\end{array}$ & $\begin{array}{l}\text { True } \\
\text { strain }\end{array}$ & $\begin{array}{l}\text { True } \\
\text { Stress } \\
(\mathbf{M P a})\end{array}$ & $\begin{array}{l}\text { True } \\
\text { strain }\end{array}$ & $\begin{array}{l}\text { True } \\
\text { Stress } \\
(\mathbf{M P a})\end{array}$ & $\begin{array}{l}\text { True } \\
\text { strain }\end{array}$ \\
\hline \multirow{2}{*}{$\begin{array}{l}\text { Al }-10 \text { beryl } \\
\text { MMC, average } \\
\text { size of beryl } \\
\text { particle size is } \\
100 \mu \mathrm{m} .\end{array}$} & 108.52 & 0.083 & 104.43 & 0.08 & 106.86 & 0.08 & 105.07 & 0.08 \\
\cline { 2 - 9 } & 112.24 & 0.096 & 107.89 & 0.09 & 108.57 & 0.09 & 109.43 & 0.09 \\
\cline { 2 - 9 } & 113.92 & 0.108 & 109.65 & 0.10 & 110.29 & 0.10 & 111.02 & 0.10 \\
\cline { 2 - 9 } & 116.21 & 0.118 & 110.62 & 0.11 & 112.79 & 0.11 & 113.01 & 0.11 \\
\cline { 2 - 9 } & 116.56 & 0.134 & 113.50 & 0.13 & 115.81 & 0.13 & 114.82 & 0.13 \\
\hline
\end{tabular}




\begin{tabular}{|l|l|l|l|l|l|l|l|l|}
\hline & 117.14 & 0.142 & 116.27 & 0.14 & 117.29 & 0.14 & 116.11 & 0.14 \\
\hline
\end{tabular}

Table 4.0 clearly shows the mechanical properties of vacuum sintered Al-10 beryl MMC. It can be seen from this table 4.0 that the load deflection curves are converted into true stress and true strain values and reported. This is the technique where all mechanical properties such as UTS, YS, $\mathrm{n}, \mathrm{k}$, and hardness values can be measured. It is worth to note that the samples size is very small and evaluation of tensile properties is difficult. By adopting ABI/BIT test, it is easy to evaluate various mechanical properties. When copper is added to Al-10 wt. \% beryl, the mechanical properties are improved and reported in Table 5. It can be seen from this Table that the true stress values are comparatively higher than the Al-10 wt. \% beryl MMC.

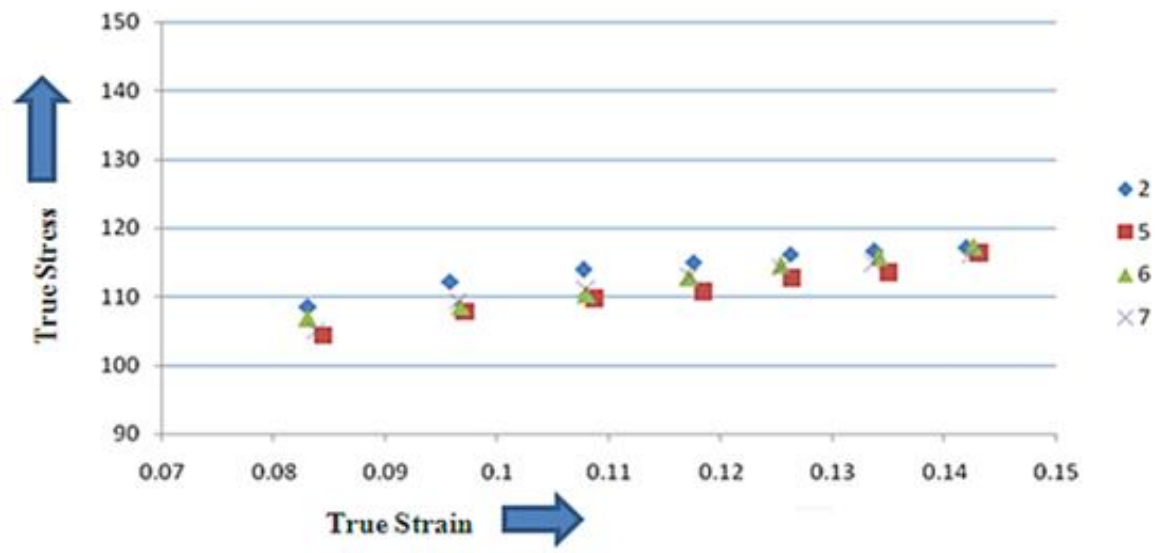

Figure 10.0: Ball indentation test result of $\mathrm{Al}$ - beryl MMC processed through vacuum sintering at a temperature of $600^{\circ} \mathrm{C}$, consisting $10 \mathrm{wt}$. \% beryl, average beryl particle size of $100 \mu \mathrm{m}$, showing true stress (MPa) versus true strain

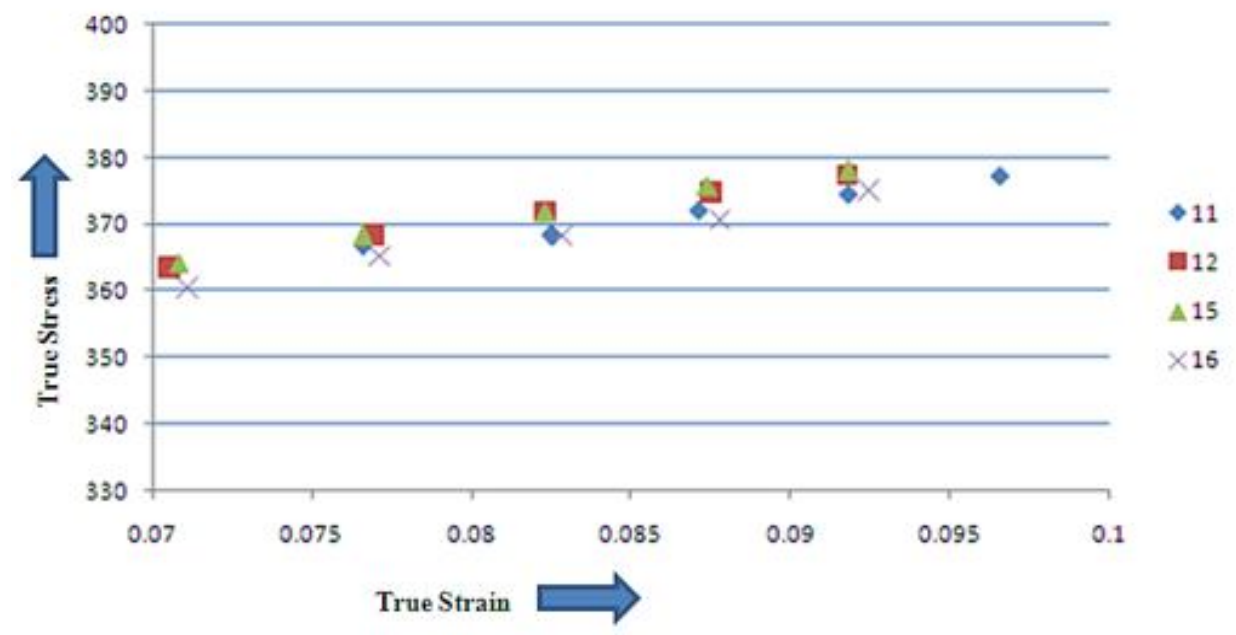

Figure 11.00: Ball indentation test result of $\mathrm{Al}-\mathrm{Cu}$ - beryl $\mathrm{MMC}$ processed through vacuum sintering at a temperature of $600^{\circ} \mathrm{C}$, consisting $20 \mathrm{wt} . \%$ beryl, and average beryl particle size is $50 \mu \mathrm{m}$, showing true stress (MPa) versus true strain

Table 5.0: Mechanical properties of Al -beryl MMC processed through vacuum sintering at a temperature of $600 \mathrm{C}$, consisting $20 \mathrm{wt}$. \% beryl, and average beryl particle size is $\mathbf{5 0 \mu m}$ 


\begin{tabular}{|c|c|c|c|c|c|c|c|c|}
\hline Sample name & $\begin{array}{l}\text { True Stress } \\
\text { (MPa) }\end{array}$ & $\begin{array}{l}\text { True } \\
\text { strain }\end{array}$ & $\begin{array}{l}\text { True } \\
\text { Stress } \\
(\text { MPa) }\end{array}$ & $\begin{array}{l}\text { True } \\
\text { strain }\end{array}$ & $\begin{array}{l}\text { True } \\
\text { Stress } \\
\text { (MPa) }\end{array}$ & $\begin{array}{l}\text { True } \\
\text { strain }\end{array}$ & $\begin{array}{l}\begin{array}{l}\text { True } \\
\text { Stress } \\
(\text { MPa) }\end{array} \\
\end{array}$ & $\begin{array}{l}\text { True } \\
\text { strain }\end{array}$ \\
\hline \multirow{8}{*}{$\begin{array}{l}\mathrm{Al}-20 \quad \text { wt. } \% \text { beryl } \\
\mathrm{MMC} \text {, }\end{array}$} & 339.83 & 0.04 & 341.73 & 0.04 & 342.15 & 0.05 & 341.17 & 0.05 \\
\hline & 351.55 & 0.05 & 350.74 & 0.05 & 352.26 & 0.06 & 350.39 & 0.06 \\
\hline & 358.13 & 0.06 & 357.52 & 0.06 & 358.75 & 0.06 & 356.64 & 0.06 \\
\hline & 363.20 & 0.07 & 363.46 & 0.07 & 364.30 & 0.07 & 360.39 & 0.07 \\
\hline & 366.83 & 0.07 & 368.30 & 0.07 & 368.37 & 0.08 & 365.11 & 0.08 \\
\hline & 368.36 & 0.08 & 371.76 & 0.08 & 371.93 & 0.08 & 368.10 & 0.08 \\
\hline & 372.16 & 0.08 & 374.73 & 0.08 & 375.70 & 0.09 & 370.56 & 0.09 \\
\hline & 374.60 & 0.09 & 377.30 & 0.09 & 378.08 & 0.09 & 375.00 & 0.09 \\
\hline
\end{tabular}

Table 6.0: Ball indentation result of $\mathrm{Al}$ - beryl MMC processed through vacuum sintering at a temperature of $600^{\circ} \mathrm{C}$, consisting $10 \mathrm{wt}$. \% beryl, and average beryl particle size is 100 $\mu \mathrm{m}$

\begin{tabular}{|l|l|l|l|l|l|l|}
\hline Sample name & $\mathbf{n}$ & K(MPa) & UTS(MPa) & YS(MPa) & YR & BHN \\
\hline \multirow{3}{*}{ Al-10 wt. \% beryl } & 0.14 & 154.19 & 102.25 & 57.44 & 56.18 & 34.94 \\
\cline { 2 - 7 } & 0.19 & 165.83 & 100.65 & 56.76 & 56.39 & 33.76 \\
\cline { 2 - 7 } & 0.18 & 166.22 & 101.95 & 57.32 & 56.22 & 34.36 \\
\cline { 2 - 7 } & 0.18 & 166.12 & 101.69 & 56.75 & 55.80 & 34.42 \\
\hline
\end{tabular}

Table 7.0: Ball indentation result of $\mathrm{Al}$ - beryl MMC processed through vacuum sintering at a temperature of $600 \mathrm{C}$, consisting $10 \mathrm{wt}$. \% beryl, and average beryl particle size is 50 $\mu \mathrm{m}$

\begin{tabular}{|l|l|l|l|l|l|l|}
\hline Sample name & $\mathbf{n}$ & K(MPa) & UTS(MPa) & YS(MPa) & YR & BHN \\
\hline \multirow{2}{*}{$\begin{array}{l}\text { Al-10 wt. \% beryl } \\
\text { composite. }\end{array}$} & 0.14 & 341.77 & 227.44 & 107.05 & 47.07 & 67.36 \\
\cline { 2 - 7 } & 0.13 & 340.48 & 228.83 & 109.87 & 48.01 & 67.77 \\
\cline { 2 - 7 } & 0.14 & 347.99 & 228.94 & 106.43 & 46.49 & 67.66 \\
\hline
\end{tabular}

Figure 7.0 (a-c) shows the optical images of Al- 10 beryl, Al- 20 beryl and Al-30 beryl composites sintered at temperature of $600^{\circ} \mathrm{C}$. The beryl particle size is $100 \mu \mathrm{m}$ and taken at $50 \mathrm{X}$. It can be seen very clearly that the number of beryl particles increased as the percentage of beryl is increased. The optical microstructural examination clearly demonstrated that vacuum sintered Al- beryl MMCs sintered at $600^{\circ} \mathrm{C}$ are responsible for porosity levels. Figure 8.0 (a-c) shows the SEM images of Al-10 beryl, Al-20 beryl and Al-30 beryl composites, consists average beryl particle size of $100 \mu \mathrm{m}$. It can be observed that porosity level is less. Figure 9.0 (a-d) shows the SEM images of vacuum sintered Al- $10 \mathrm{wt}$ \% beryl composites, consist of average beryl particle size of $110 \mu \mathrm{m}$ at different magnifications. At higher magnifications, a close observation clearly demonstrates that a porosity levels exists and also observed that the interfacial bonding between beryl particle and Al matrix is good. To compare these results with high beryl content, 
experiments are carried out on samples on Al-20 beryl is shown in table 5.0. It can be observed that there is drastic change as the particle size is reduced to $50 \mu \mathrm{m}$ and volume fraction of beryl is increased. The actual BIT test results for the Al-10 beryl MMC processed through microwave sintering at a temperature of $600^{\circ} \mathrm{C}$, consisting $10 \mathrm{wt}$. \% beryl, average beryl particle size of 100 $\mu \mathrm{m}$, showing true stress (MPa) versus true strain is shown in figure 10.0. Figure 11.0 shows the Ball indentation test result of Al- $20 \mathrm{wt}$. \% beryl MMC processed through microwave sintering at a temperature of $600^{\circ} \mathrm{C}$, consisting $20 \mathrm{wt} . \%$ beryl, average beryl particle size of $50 \mu \mathrm{m}$, showing true stress $(\mathrm{MPa})$ versus true strain. It can be seen that true stress levels for $10 \mathrm{wt}$ \% beryl, with average beryl particle size of $100 \mu \mathrm{m}$ exhibited $120 \mathrm{MPa}$, and increased to $375 \mathrm{MPa}$ after volume fraction is increased to $20 \mathrm{wt}$. \% beryl, with average beryl particle size is $50 \mu \mathrm{m}$.

Table 6.0 shows the mechanical properties of Al-10 beryl MMC with an average beryl particle size of $100 \mu \mathrm{m}$. It can be seen from this result, UTS value is $\sim 102 \mathrm{MPa}$ with YS of $\sim 57 \mathrm{MPa}$. To compare the influence of particle size with same Al- $10 \mathrm{wt}$ \% beryl MMC and mechanical properties are reported in Table 7.0. As the beryl particle size is reduced to $50 \mu \mathrm{m}$, there is drastic increase in strength properties. These result suggest that fine beryl particles act as dislocation barriers and responsible for improved hardness and strength values. $\mathrm{K}$ values are increased in accordance with yield and UTS values. It is clear from these studies that the copper content played a major role in improving mechanical properties. We have only considered 5 wt. $\%$ copper additions and it is recommended to study various compositions and optimum copper content can be evaluated. It is shown the true stress values have been substantially increased by just adding 5 wt. \% copper to Al-10 beryl MMC.

\subsection{Wear results}

The wear properties of vacuum and microwave sintered Al-10, 20, 30 beryl with sintering temperature of $600^{\circ} \mathrm{C}$ are chosen for study. Sample A refers to the beryl particle size of $100 \pm 10$ $\mu \mathrm{m}$, sample ID C1, C2, C3 corresponds to Al- 10 beryl, Al-20 beryl and Al-30 beryl. The experimental conditions during dry sliding wear test are $0.5 \mathrm{~kg}$ and $1.0 \mathrm{~kg}$ applied load, $2000 \mathrm{~m}$ sliding distance, $90 \mathrm{~mm}$ track diameter and $100 \mathrm{rpm}$ speed. Table 8.0 shows various composition of beryl and average size of the beryl particles in Al- beryl MMCs.

Table 8.0: Various compositions and average size of the beryl particle size of Al- beryl MMCs

\begin{tabular}{|c|c|c|c|c|}
\hline \multirow[t]{2}{*}{$\begin{array}{l}\text { SI } \\
\text { No }\end{array}$} & \multirow[t]{2}{*}{ Sample } & \multirow[t]{2}{*}{ Sample ID } & \multicolumn{2}{|c|}{$\begin{array}{l}\text { Composition, } \\
\text { wt. } \%\end{array}$} \\
\hline & & & Al & Beryl \\
\hline 1 & Al-10 beryl & $\mathrm{AC} 1$ & 90 & 10 \\
\hline 2 & Al-20 beryl & $\mathrm{AC} 2$ & 80 & 20 \\
\hline 3 & Al-30 beryl & $\mathrm{AC} 3$ & 70 & 30 \\
\hline
\end{tabular}




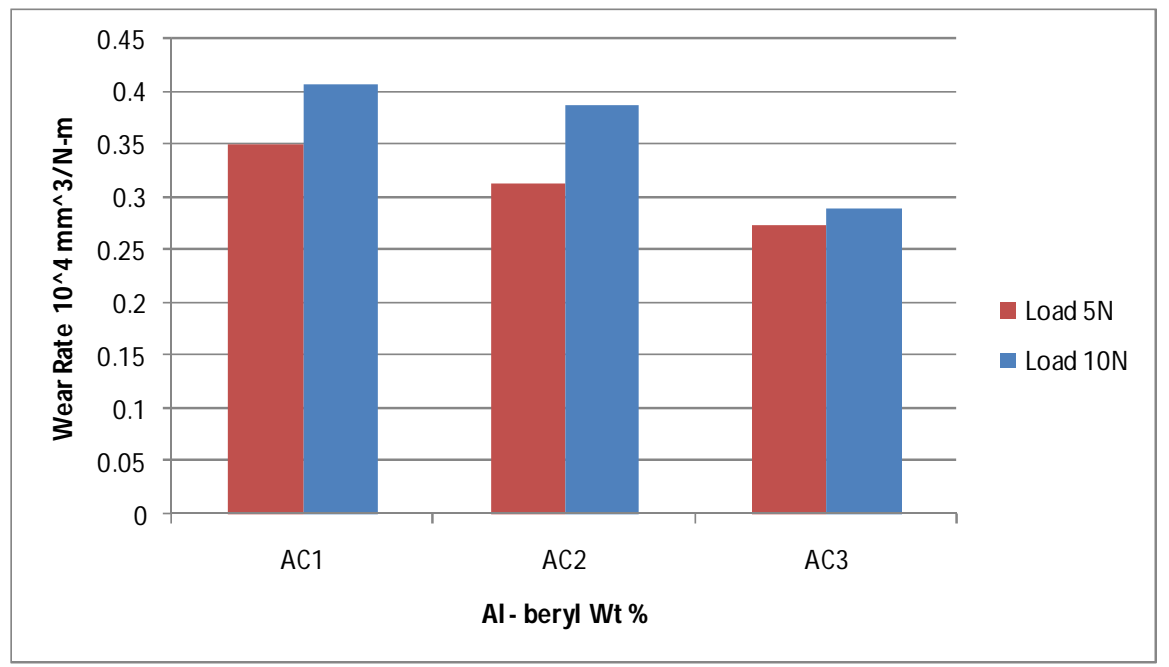

Figure 12.0: Effect of load on microwave sintered $\mathrm{Al}$ - beryl MMCs

Figure 12.0 shows the variation of beryl content in Al-beryl MMCs. It can be seen from this bar chart that the increase in beryl content from 10 to $30 \mathrm{wt}$. \% has substantially improved the sliding wear resistance. Al-30 beryl MMC has shown reduced wear rate as compared to Al-10 beryl MMC. These results further suggest that the beryl content has played a significant role in protecting the matrix by absorbing the load transmitted during sliding action. As a result, lower wear rate or high wear resistance has been observed for Al-30 beryl MMC. Moreover, high applied of $10 \mathrm{~N}$ showed more wear rate as compared to $5 \mathrm{~N}$ applied load. The same results are depicted in Fig.13.0. Further, it is suggested that sliding wear performance of Al-beryl MMCs are greatly controlled by particle, applied load and beryl content.

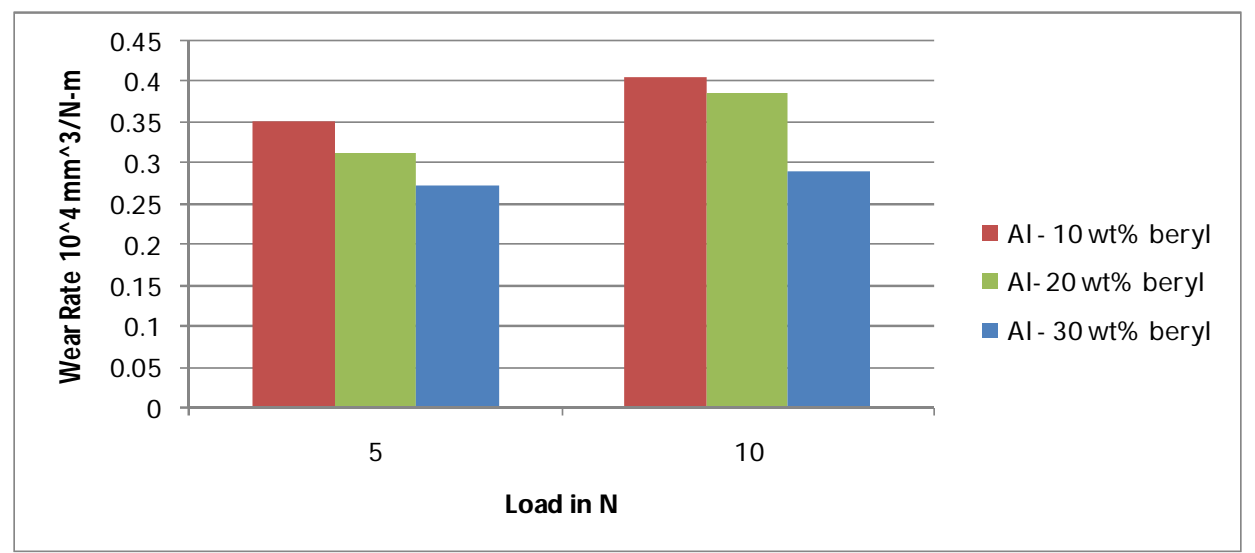

Figure 13.0: Effect of beryl percentage on microwave sintered $\mathrm{Al}$ - beryl MMCs 
It can be observed that the wear rate decreases when the percentage of beryl is increased. The decrease in wear rate with increase in the percentage of beryl can be observed which is due to the presence of hard beryl particles adhered to the matrix[10,11].It can also be observed from the figures that, there is increase in the resistance to wear with increase in the percentage of beryl which is of prime importance in the wear resistant applications. With the increase in sliding distance, weight loss increases due to more amount of time in wearing $[12,13]$.

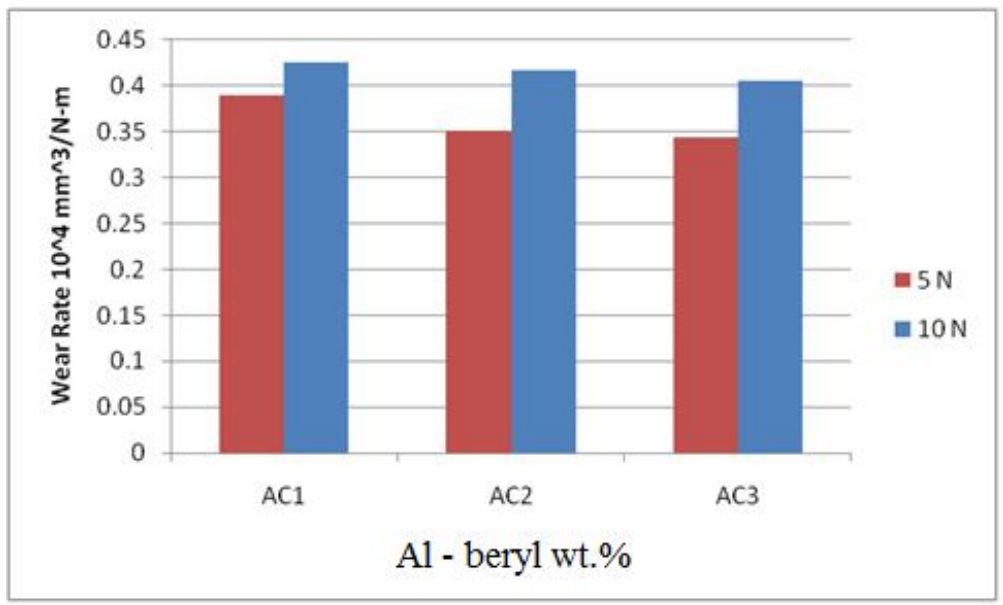

Figure 14.0: Effect of load on vacuum sintered $\mathrm{Al}$ - beryl MMCs

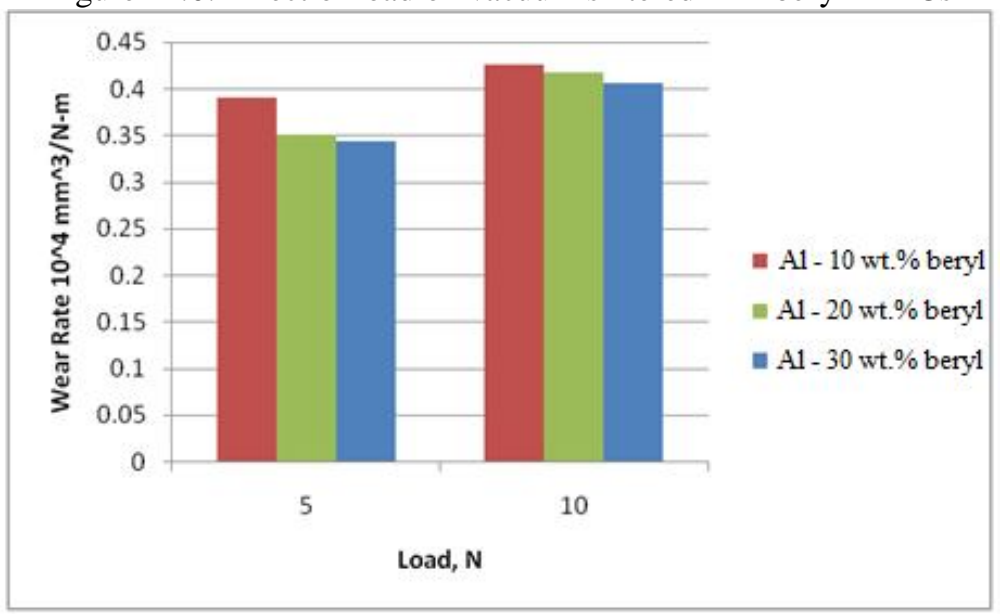

Figure 15.0: Effect of percentage on vacuum sintered $\mathrm{Al}$ - beryl MMCs

Figure 14.0 and 15.0 shows the influence of beryl content and different applied load during the sliding wear performance tests of Al-beryl MMCs prepared by vacuum sintering technique. It can be seen from Fig. 4.98 that increase in beryl content from 10 to $30 \mathrm{wt} \%$ is responsible for reduced wear rate results. Moreover, the increased applied load from $5 \mathrm{~N}$ to $10 \mathrm{~N}$ resulted in increased wear rate results. Since the beryl content showed improved wear resistance results, an attempt is made to study the machinability of these Al-beryl MMCs and these composites are machined using conventional tool nits. It is very clear from these studies that it is very difficult to machine these newly developed Al-beryl MMCs as the toll life is drastically reduced and further attempt is made use the diamond tip tool bits. Similar results are observed and it is intended to 
carry out a detailed study on influence of beryl content its composition on machinability performance. A detailed study on sliding wear performance of these composites is in progress. As a result, these detailed works are shown as future scope of work.

\section{CONCLUSIONS}

Al based beryl reinforced MMCs have been successfully synthesized by powder metallurgy route, using vacuum and microwave sintering. Al-10, 20, 30 beryl MMCs were successfully synthesized powder metallurgy using vacuum and microwave sintering methods and the powder metallurgy route is established as an alternative route compared to squeeze or stir casting routes. Al-beryl MMCs synthesized by PM route using microwave sintering showed superior mechanical and wear properties than Al-beryl MMCs synthesized by same route sintered using vacuum sintering. So, the process selection and parameters have been optimized through this study. Microstructural examination of microwave sintered Al- beryl MMCs, demonstrate the uniform distribution of beryl particles in Al matrix with less porosity compare to vacuum sintered Al- beryl MMCs synthesized by same route. Microstructural examination of microwave sintered Al- beryl MMCs synthesized by powder metallurgy route reveals that the interfacial bonding between the beryl particles and Al- matrix is good and that also been established from the mechanical properties. Microwave sintered Al- beryl MMCs fabricated with PM route with average beryl particle size of $50 \mu \mathrm{m}$ showed superior wear properties compare to average beryl particle size of $110 \mu \mathrm{m}$. So, the optimization for its machinability is also directed by this study and to be established with complementary sliding wear studies.

\section{ACKNOWLEDGMENTS}

The authors sincerely thank Dr Gowtham Das, National Metallurgical Laboratory (NML) for conducting Ball indentation test, Dr. L. Rangaraj, Sr Principal Scientist, CSIR- National Aerospace Laboratories, Bangalore for carrying out sintering work. The authors also thank Jain University, the Management Panchajanya Vidya Peetha Welfare Trust (Regd), Dr. C. Nanjundaswamy, Principal of Dr. Ambedkar Institute of Technology, Bengaluru, the management, M S Ramaiah Institute of Technology, Bengaluru. The authors sincerely thank Dr. N.J. Krishnaprasad, Bangalore Institute of Technology, Bangalore for his immense scientific help.

\section{REFERENCES}

[1]. C. Wei and P.F.Becher, "Development of SiC-whisker-reinforced ceramics, Am, Ceram, Soc. Bull., 64 (1985) 298-304

[2]. S. Gururaja, M. Ramulu, W. Pedersen, Machining of MMCs: a review, Mach. Sci. Technol. 17 (1) (2013) 4173.

[3]. B.S. Yigezu, P.K. Jha, M.M. Mahapatra,The Key Attributes of Synthesizing Ceramic Particulate Reinforced Al-Based Matrix Composites through Stir Casting Process: A Review, Mater Manuf Process, 28 (2013) 969979.

[4]. Rehman, S. Das, G. Dixit, Analysis of stir die cast Al-SiC composite brake drums based on coefficient of friction, Tribol Int, 51 (2012) 36-41.

[5]. J.J. Park, S.H. Lee, M.K. Lee, C.K. Rhee, Dispersion of ultrafine SiC particles in molten Al-12Si alloy, T Nonferr Metal Soc, 21 (2011) S33-S36.

[6]. P. Zhang, F.G. Li, Effects of Particle Clustering on the Flow Behavior of SiC Particle Reinforced Al Metal Matrix Composites, Rare Metal Mat Eng., 39 (2010) 1525-1531.

[7]. P. Zhang, X. Nie, H. Henry, J. Zhang, Preparation and tribological properties of thin oxide coatings on an Al383/SiO2 metallic matrix composite, Surface and Coatings Technology, Vol. 205 (2010) 1689-1696. 
[8]. N.R.P. Swamy, C.S. Ramesh, T. Chandrasekhar, Effect of heat treatment on strength and abrasive wear behaviour of Al6061-SiCp composites, B Mater Sci, 33 (2010) 49-54.

[9]. B.S. Yigezu, P.K. Jha, M.M. Mahapatra,The Key Attributes of Synthesizing Ceramic Particulate Reinforced Al Based Matrix Composites through Stir Casting Process: A Review, Mater Manuf Process, 28 (2013) 969979.

[10]. A. Rehman, S. Das, G. Dixit,Analysis of stir die cast Al-SiC composite brake drums based on coefficient of friction, Tribol Int, 51 (2012) 36-41.

[11]. J.J. Park, S.H. Lee, M.K. Lee, C.K. Rhee,Dispersion of ultrafine SiC particles in molten Al-12Si alloy, T Nonferr Metal Soc, 21 (2011) S33-S36.

[12]. P. Zhang, F.G. Li,Effects of Particle Clustering on the Flow Behavior of SiC Particle Reinforced Al Metal Matrix Composites, Rare Metal Mat Eng, 39 (2010) 1525-1531

[13]. P. Deshmukh, S. Pathak,Influence of Varying SiO2 \% on the Mechanical Properties of Al Based MMC, T Indian I Metals, 65 (2012) 741-745.

[14]. N.R.P. Swamy, C.S. Ramesh, T. Chandrashekar,Effect of heat treatment on strength and abrasive wear behaviour of Al6061-SiCp composites, B Mater Sci, 33 (2010) 49-54.

[15]. G. Ferraris, M. Prencipe, P. Rossi,Stoppaniite, a new member of the beryl group; crystal structure and crystal chemical implications, Eur J Mineral, 10 (1998) 491-496.

[16]. H.N. Reddappa, H.B. Niranjan, K.R. Suresh, K.G. Satyanarayana,Effect of Quenching Media and Ageing Time on Al6061-Beryl Composites, Mechanical and Aerospace Engineering, Pts 1-7, 110-116 (2012) 13741379.

[17]. H.N. Reddappa, K.R. Suresh, H.B. Niranjan, K.G. Satyanarayana,Effect of Rolling On Microstructure and Wear Behavior of Hot Rolled Al6061-Beryl Composites, Advanced Materials Research Ii, Pts 1 and 2, 463464 (2012) 444-448.

[18]. G. Elango, B.K. Raghunath, K. Palanikumar, K. Thamizhmaran, Sliding wear of LM25 aluminium alloy with $7.5 \% \mathrm{SiC}+2.5 \% \mathrm{TiO}_{2}$ and $2.5 \% \mathrm{SiC}+7.5 \% \mathrm{TiO}_{2}$ hybrid composites, J Compos Mater, 48 (2014) 22272236.

[19]. M. Uthayakumar, S. Aravindan, K. Rajkumar, Wear performance of Al-SiC-B4C hybrid composites under dry sliding conditions, Mater Design, 47 (2013) 456-464.

[20]. T. Nakase, S. Kato, T. Kobayashi, S. Sasaki, Tribological properties of aluminium-12 wt.\% silicon alloy surface treated with dispersed hard particles during sliding against different steels, P I Mech Eng. J-J Eng., 227 (2013) 423-432.

[21]. R.N. Yadav, V. Yadava, Machining Performance of Slotted-Electrical Discharge Diamond Face Grinding of Al/SiC/Gr Composite, Mater Manufacturing Process, 29 (2014) 585-592. 